\title{
EFEKTIVITAS VARIABEL MEDIATOR BERDASARKAN KONTRIBUSINYA DALAM MODEL MEDIASI SEDERHANA
}

\author{
Deddy A. Suhardi (deddy_as@mail.ut.ac.id) \\ Isfarudi (isfarudi@mail.ut.ac.id) \\ Jurusan Statistika, FMIPA, Universitas Terbuka
}

\begin{abstract}
Structurally relationship of variables is important in deeply analysis of path models, but the process of effect distribution must be concerned. In this situation, one or more variable would be a mediator variable which assessing effect of an independent to a dependent variable. We studied the simple mediation model that is one of path analytical models which contain of one independent variable, dependent variable and mediator variable. A necessary component of mediation is effectiveness that is a statistically significant indirect effect, formal significance tests of indirect effects are early conducted by Sobel (1982). According to sequential regression analysis on a simple mediation model, a mediator variable come after an independent variable exist in the model, the contribution of upcoming variable to the model could be obtained. We argue the importance of investigating empirical relationship between the significance of indirect effects and sequential contribution of mediator variable with a normal theory approach using Microsoft Excel simulation tools developed by Myerson (2000). We find that the higher contribution of mediator variable to the model, the more effectiveness is. This result comes up with three level correlation of independent and dependent variable which each 1000 times iteration that gives relatively immediate information about the recent empirical relationship between the significance of indirect effects and sequential contribution of mediator in the simple mediation models.
\end{abstract}

Keywords : sequential regression, simple mediation models, sobel test

Penelitian-penelitian di bidang sosial atau ekonomi sering kali berpijak pada model yang mengandung banyak variabel. Analisis model yang mendalam tidak saja menyangkut struktur hubungan variabel-variabel dalam model, tetapi juga tatanan variabel-variabel dalam model yang menggambarkan proses pendistribusian pengaruh melalui jalur-jalur hubungan. Misalnya, seperti yang dikemukakan oleh Preacher dan Hayes (2004), suatu manajemen perusahaan menganggap sangat penting mengetahui apakah program pelatihan manajemen mendorong peningkatan pada kepuasan hasil kerja karyawan dengan memperbaiki kemampuan karyawan atau mengubah pola kebiasaan hidup karyawan. Dalam contoh ini, kemampuan karyawan dan kebiasaan karyawan potensial menjadi variabel-variabel perantara (mediator) hubungan antara program pelatihan dengan kepuasan hasil kerja.

Suatu variabel dikatakan sebagai mediator karena berperan menghantarkan pengaruh perubahan variabel bebas terhadap variabel lain sebagai variabel respons. Perubahan yang diharapkan pada suatu variabel respons dipandang sebagai implikasi dari perubahan yang dilakukan terhadap variabel bebas yang mendorong terjadinya perubahan dalam variabel mediator. 
Peranan suatu variabel mediator dalam penelitian ini dikaji melalui suatu model mediasi sederhana, yaitu suatu model yang terdiri atas masing-masing satu variabel bebas $(X)$, variabel respons $(Y)$, dan variabel mediator $(M)$. Sebelum adanya variabel $M$, tatanan hubungan dalam model hanya mengandung satu hubungan sederhana yaitu hubungan $X$ terhadap $Y$. Adanya variabel $M$ dalam model mediasi sederhana dipandang sebagai penambahan satu variabel baru terhadap model hubungan sederhana $X$ dengan $Y$.

Penambahan variabel $\mathrm{M}$ ke dalam model dapat diukur kontribusinya dalam menerangkan keragaman $Y$ yang sebelumnya hanya diterangkan oleh keragaman $\mathrm{X}$. Kontribusi $\mathrm{M}$ mempunyai kontribusi yang cukup tinggi maka diharapkan keragaman $Y$ yang dapat diterangkan menjadi meningkat. Semakin tinggi kontribusi M setelah adanya $X$ dalam model maka diharapkan semakin tinggi pula keragaman Y dapat diterangkan.

Dalam penelitian ini, suatu variabel mediator dalam model hubungan mediasi sederhana dikaji efektivitasnya sehubungan dengan kontribusinya dalam model. Bagaimana efektivitas variabel mediator pada berbagai kondisi kontribusi variabel mediator ke dalam model regresi sederhana? Dengan perkataan lain, apakah efektivitas suatu variabel mediator dalam model mediasi sederhana dipengaruhi oleh kontribusinya?

Penelitian ini ingin menguji konsistensi hubungan antara kontribusi variabel mediator dan signifikansi pengaruh mediasinya, serta menentukan rata-rata titik kritis tingkat kontribusi variabel mediator yang pengaruh mediasinya signifikan. Hasil penelitian ini diharapkan dapat menentukan efektivitas variabel mediator berdasarkan informasi tingkat kontribusinya dalam model mediasi sederhana.

Suatu variabel dapat berperan sebagai suatu variabel mediator (M) yang dapat menghantarkan pengaruh suatu variabel bebas tertentu $(X)$ kepada suatu variabel respons tertentu (Y). Mediasi ini terjadi ketika (i) $X$ signifikan mempengaruhi $M$, (ii) $X$ signifikan mempengaruhi $Y$ tanpa adanya mediator, (iii) M mempunyai suatu pengaruh unik yang signifikan terhadap $Y$, dan (iv) pengaruh $X$ kepada $Y$ tergantung penambahan mediator ke dalam model (Preacher \& Leonardelli, 2006). Kriteria ini dapat digunakan untuk menilai ada/tidaknya mediasi terjadi, tetapi untuk lebih formalnya dapat dilaksanakan dengan metode mediation test (MacKinnon \& Dwyer, 1993; dan MacKinnon, Warsi, \& Dwyer, 1995).

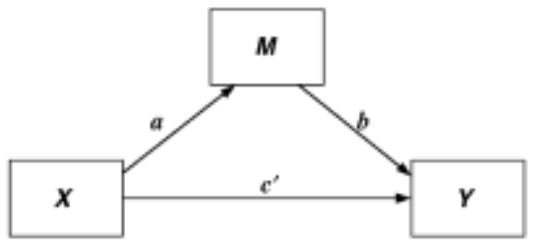

Gambar 1. Model mediasi sederhana : Pengaruh $\mathrm{X}$ terhadap $\mathrm{Y}$ melalui $\mathrm{M}$.

(Sumber : Preacher \& Hayes, 2004, Behavior Research Methods, Instruments, \& Computers, 36 (4), 717-731)

Hubungan sederhana antara $X$ dan $Y$ sering digambarkan sebagai pengaruh $X$ terhadap $Y$ yang lebih dikenal sebagai koefisien regresi sederhana $X$ terhadap $Y$ (misalkan koefisien regresi adalah c). Sistem mediasi sederhana ditunjukkan pada Gambar 1, penambahan variabel mediator M akan mengubah pengaruh $\mathrm{X}$ terhadap $\mathrm{Y}$ dari $\mathrm{c}$ menjadi c' karena dianggap $\mathrm{X}$ berpengaruh terhadap 
M. Variabel M dipertimbangkan sebagai mediator jika (i) $X$ signifikan berpengaruh terhadap $Y$, (ii) $X$ signifikan berpengaruh terhadap $M$ (koefisien $a \neq 0$ ), dan (iii) M signifikan berpengaruh terhadap $Y$ setelah dikontrol variabel $X$ (koefisien $b \neq 0$ ). Baron and Kenny (1986) menggambarkan suatu prosedur statistik yang dikembangkan oleh Sobel (1982) dengan menganalisis sistem pengaruh mediasi melalui model-model persamaan regresi sebagai berikut

(1) $Y=i_{1}+c X+\varepsilon_{1}$

(2) $M=i_{2}+a X+\varepsilon_{2}$

(3) $Y=i_{3}+c^{\prime} X+b M+\varepsilon_{3}$

$i$ adalah koefisien intersep dan $\varepsilon$ adalah komponen galat (error term). Ketika pengaruh $X$ terhadap $Y$ mendekati nol dimana M ada dalam model (nilai $c^{\prime}=0$ pada persamaan (3)), maka terjadi mediasi sempurna dari M (James \& Brett, 1984). Ketika pengaruh parsial X terhadap Y mendekati angka tertentu tetapi tidak nol, maka terjadi mediasi parsial.

Koefisien $c$ adalah koefisien regresi antara $Y$ dan $X$, sedangkan koefisien c' adalah koefisien regresi parsial antara $Y$ dengan $X$ pada model (3). Koefisien $c$ belum tentu identik dengan koefisien $c$ ', hal ini sangat tergantung pada korelasi antara $X$ dengan $M$, koefisien tersebut akan bernilai sama manakala $X$ dengan $M$ tidak berkorelasi.

Koefisien $b$ adalah koefisien regresi parsial antara $Y$ dengan $M$, yaitu koefisien regresi setelah variasi $Y$ dan $M$ dikoreksi terlebih dahulu oleh adanya variabel $X$. Atau dengan kata lain, jika dicatat $\hat{Y}=i_{1}+c X$ dan $\varepsilon_{1}=\varepsilon(Y \mid X)=Y-\hat{Y}$, maka $b$ adalah koefisien regresi antara $\varepsilon_{1}$ dengan $\varepsilon_{2}=\varepsilon(M \mid X)=M-\hat{M}$ (lihat model (1) dan (2)). Seandainya $X$ dengan $M$ tidak berkorelasi maka $\varepsilon_{2}=M$, dan $b$ akan sama dengan koefisien regresi sederhana antara $Y$ dan $M$.

Prosedur uji statistik hipotesis mediasi (yang kemudian disebut sebagai Sobel Test) dalam sistem mediasi sederhana seperti pada Gambar 1. Uji ini membandingkan kekuatan pengaruh tidak langsung $X$ terhadap $Y$ dengan hipotesis null yang menyatakan bahwa pengaruh tersebut sama dengan nol. Pengaruh tidak langsung $X$ terhadap $Y$ didefinisikan sebagai pengaruh $X$ terhadap $M$ kali pengaruh $M$ terhadap $Y$, atau $a b$. Dalam hal ini $a b=c-c^{\prime}$, dimana $c$ adalah pengaruh sederhana $X$ terhadap $Y$ (tanpa mengontrol $M$ ), dan c' adalah pengaruh $X$ terhadap $Y$ setelah adanya $M$ dalam model. Standar error $a$ dan $b$ masing-masing adalah $s_{a}$ dan $s_{b}$. Standar error pengaruh tidak langsung adalah $s_{a b}$ sebagai

(4) $s_{a b}=\sqrt{b^{2} s_{a}^{2}+a^{2} s_{b}^{2}+s_{a}^{2} s_{b}^{2}}$.

Statistik uji untuk pengujian hipotesis adalah

(5) $Z=\frac{a b}{s_{a b}}$

di bawah hipotesis null rasio ini mendekati distribusi normal standar, dan uji hipotesis dilakukan dengan membandingkan rasio ini dengan nilai dari distribusi normal standar dengan peluang tertentu (Sobel, 1982). 
Model (1), (2), dan (3) adalah model regresi secara umum dapat ditulis $Y=X \boldsymbol{\beta}+\boldsymbol{\varepsilon}$, $Y=$ vektor pengamatan berukuran $n \times 1, X=$ matriks prediktor berukuran $n \times p, p=k+1, k=$ banyaknya prediktor, $\beta=$ vektor parameter berukuran $p \times 1$, dan $\varepsilon$ vektor galat (error term) berukuran $n \times 1$ nilai tengah nol dan variansi homogen. Penduga koefisien regresi $\boldsymbol{\beta}$ adalah vektor $\hat{\boldsymbol{\beta}}$, sehingga taksiran model regresi adalah $\hat{\boldsymbol{Y}}=\boldsymbol{X} \hat{\boldsymbol{\beta}}$ (Myers \& Milton, 1991).

Variasi $Y$ sebelum adanya faktor $X$ dalam model dilihat dari besaran $\sum(Y-\bar{Y})^{2}$ yaitu jumlah kuadrat totalnya; dengan adanya $X$ dalam model maka $Y$ diduga oleh model $\hat{\boldsymbol{Y}}=\boldsymbol{X} \hat{\boldsymbol{\beta}}$ dan pengukur variasinya sekarang adalah $\sum(Y-\hat{Y})^{2}$ sehingga dapat dilihat besarnya pengurangan variasi tersebut atau rasio antara $\sum(Y-\hat{Y})^{2}$ terhadap $\sum(Y-\bar{Y})^{2}$ yang diharapkan menjadi semakin kecil. Analisis penilaian model dan sumber-sumber variasi $Y$ dapat dilakukan melalui Analysis of Variance (Anova). Anova menyajikan dua komponen sumber variasi $Y$ yaitu komponen model regresi dan komponen galat. Besarnya sumbangan sumber-sumber variasi diukur oleh jumlah kuadrat masing-masing. Rasio antara jumlah kuadrat model regresi dengan jumlah kuadrat total, merupakan ukuran ketepatan model regresi yang disebut dengan koefisien determinasi $\left(R^{2}\right)$, bernilai antara 0 sampai 1 . Jumlah kuadrat model regresi diharapkan besar mendekati jumlah kuadrat total sehingga $R^{2}$ mendekati satu.

Pendugaan koefisien regresi dapat dilakukan melalui analisis terhadap matrik kovariansi (Morrison, 1990). Misalkan tersedia sampel acak $Y, X_{1}, X_{2}, \ldots, X_{k}$ masing-masing berukuran $n$ pengamatan, ditulis dalam bentuk matrik yang dipartisi menjadi dua bagian, bagian pertama terdiri atas peubah $Y$ dan bagian kedua terdiri atas $k$ peubah-peubah $X$, maka matrik kovariansi sampel sesuai partisi tersebut adalah sebagai berikut

$$
\mathbf{S}=\left(\begin{array}{cc}
s_{Y}^{2} & \mathbf{s}_{Y X}^{\prime} \\
\mathbf{s}_{Y X} & \mathbf{S}_{X X}
\end{array}\right)
$$

Penduga koefisien regresi adalah vektor $\hat{\boldsymbol{\beta}}=\left(\hat{\beta}_{1}, \hat{\beta}_{2}, \ldots \hat{\beta}_{k}\right)^{\prime}$ yang berukuran $1 \mathrm{x}$ adalah

(6) $\hat{\boldsymbol{\beta}}=\mathbf{S}_{X X}^{-1} \mathbf{S}_{Y X}$

dan $R^{2}$ adalah

(7) $R^{2}=\frac{\mathbf{s}_{Y X}^{\prime} \mathbf{S}_{X X}^{-1} \mathbf{S}_{Y X}}{s_{Y}^{2}}$.

Koefisien regresi (parsial) $\hat{\beta}_{j}, j=1,2, \ldots, k$, mempunyai distribusi dengan nilai tengah $\beta_{j}$ dan variansi $\sigma_{\hat{\beta}_{j}}^{2}$, yang dari sampel diduga dengan $\mathrm{s}_{\hat{\beta}_{j}}^{2}$. Misalkan peubah-peubah disusun sebagai $Y, X j, X q^{\prime}=[X 1, \ldots, X j-1, X j+1, \ldots, X k]$, simbol $q$ melambangkan urutan indeks peubah-peubah setelah $Y$ dan $X_{j}$, yaitu $1, \ldots, j-1, j+1, \ldots, k$. Variansi bersyarat sampel untuk $X_{j}$ didefinisikan (Morrison, 1990) sebagai 
(8) $s_{j . q}^{2}=s_{j}^{2}\left(1-\mathrm{R}_{j . q}^{2}\right)=s_{j}^{2}-\mathbf{S}_{j q}^{\prime} \mathbf{S}_{q q}^{-1} \mathbf{S}_{j q}$

dan penduga variansi $\sigma_{\hat{\beta}_{j}}^{2}$ adalah

(9) $s_{\hat{\beta}_{j}}^{2}=\frac{s_{Y}^{2}\left(1-R^{2}\right)}{(n-k-1) s_{j . q}^{2}}$.

Dalam model mediasi sederhana, dapat disusun sampel acak $Y, M, X$ masing-masing berukuran $n$ pengamatan, dengan matrik kovariansinya adalah

(10) $\mathbf{S}=\left(\begin{array}{ccc}s_{Y}^{2} & s_{Y M} & s_{Y X} \\ s_{Y M} & s_{M}^{2} & s_{M X} \\ s_{Y X} & s_{M X} & s_{X}^{2}\end{array}\right)$

Jika matrik pengamatan $Y, M, X$ ditulis dalam bentuk matrik yang dipartisi menjadi dua bagian, bagian pertama terdiri atas peubah $Y$ dan bagian kedua (misalkan $\mathrm{U}$ ) terdiri atas peubah $\mathrm{M}$ dan $\mathrm{X}$, maka matrik kovariansi sampel sesuai partisi tersebut adalah $\mathbf{S}=\left(\begin{array}{cc}s_{Y}^{2} & \mathbf{s}_{Y U}^{\prime} \\ \mathbf{s}_{Y U} & \mathbf{S}_{U U}\end{array}\right), \mathbf{s}_{Y U}^{\prime}=\left(\begin{array}{ll}s_{Y M} & s_{Y X}\end{array}\right)$ $\operatorname{dan} \mathbf{S}_{U U}=\left(\begin{array}{cc}s_{M}^{2} & s_{M X} \\ s_{M X} & s_{X}^{2}\end{array}\right)$

Penduga koefisien regresi untuk peubah $M$ dan $X$ pada model (3) adalah

(11) $\hat{\boldsymbol{\beta}}=\mathbf{S}_{U U}^{-1} \mathbf{S}_{Y U}$

$$
\left(\begin{array}{l}
b \\
c^{\prime}
\end{array}\right)=\left(\begin{array}{cc}
s_{M}^{2} & s_{M X} \\
s_{M X} & s_{X}^{2}
\end{array}\right)^{-1}\left(\begin{array}{c}
s_{Y M} \\
s_{Y X}
\end{array}\right)
$$

dengan

(12) $R^{2}=\frac{\mathbf{s}_{Y U}^{\prime} \mathbf{S}_{U U}^{-1} \mathbf{s}_{Y U}}{s_{Y}^{2}}$

$$
\begin{gathered}
=\frac{1}{s_{Y}^{2}}\left(\begin{array}{ll}
s_{Y M} & s_{Y X}
\end{array}\right)\left(\begin{array}{cc}
s_{M}^{2} & s_{M X} \\
s_{M X} & s_{X}^{2}
\end{array}\right)^{-1}\left(\begin{array}{c}
s_{Y M} \\
s_{Y X}
\end{array}\right) \\
=\frac{1}{s_{Y}^{2}}\left(\begin{array}{ll}
s_{Y M} & s_{Y X}
\end{array}\right)\left(\begin{array}{c}
b \\
c^{\prime}
\end{array}\right) .
\end{gathered}
$$


Untuk model (2), pendugaan koefisien regresi sederhana $X$ terhadap $M$, dapat dilakukan menggunakan matrik kovariansi $\mathbf{S}_{U U}=\left(\begin{array}{cc}s_{M}^{2} & s_{M X} \\ s_{M X} & s_{X}^{2}\end{array}\right)$. Koefisien regresi a, R2, dan $s_{a}^{2}$ dari model ini masing-masing adalah

(13) $a=\left(s_{X}^{2}\right)^{-1} s_{M X}$

(14) $R_{M \mid X}^{2}=\frac{s_{M X}^{\prime}\left(s_{X}^{2}\right)^{-1} s_{M X}}{s_{M}^{2}}$

Variansi sampel bersyarat $M$ setelah $X$ dengan menggunakan persamaan (7) adalah

(15) $s_{M \mid X}^{2}=s_{M}^{2}\left(1-R_{M \mid X}^{2}\right)$

sehingga dengan menggunakan persamaan (8) diperoleh

(16) $s_{a}^{2}=\frac{s_{M \mid X}^{2}}{(n-2) s_{X}^{2}}$

Penduga variansi dari $\hat{\boldsymbol{\beta}}=\left(b, c^{\prime}\right)^{\prime}$ dalam model (3) juga diperoleh melalui persamaan (8). Penduga variansi koefisien regresi $b$ diperoleh dengan menggunakan (9), (12) dan (15), yaitu

(17) $s_{b}^{2}=\frac{s_{Y}^{2}\left(1-R^{2}\right)}{(n-2-1) s_{M \mid X}^{2}}$

Selanjutnya, dengan hasil-hasil di atas dapat diperoleh statistik Sobel Test (Z) dengan menggunakan persamaan (11), (13), (16), (17), dan (5).

Jumlah kuadrat regresi dapat dipartisi tergantung urutan masuknya prediktor dalam model (sekuensial). Jumlah kuadrat sekuensial (extra sums of square) penambahan suatu prediktor ke dalam model merupakan ukuran kontribusi masuknya prediktor tersebut. Misalkan, setiap prediktor secara berurutan satu per satu masuk dalam model sampai terbentuk model regresi yang terdiri atas k prediktor, $y=\beta_{0}+\beta_{1} X_{1}+\ldots+\beta_{k} X_{k}+\varepsilon$, dengan jumlah kuadrat regresi $J K R\left(\beta_{0}, \beta_{1}, \ldots, \beta_{k}\right)$. Jumlah kuadrat sekuensial penambahan parameter prediktor $X_{j}, j \in 1, \ldots, k$ ke dalam model $y=\beta_{0}+\beta_{1} X_{1}+\ldots+\beta_{j-1} X_{j-1}+\varepsilon$ disebut "extra sums of square" adalah

(18) $J K R\left(\beta_{j} \mid \beta_{0}, \beta_{1},{ } \beta_{j-1}\right)=J K R\left(\beta_{0}, \beta_{1},{ }_{0} \beta_{j}\right)-J K R\left(\beta_{0}, \beta_{1}, . \beta_{j-1}\right)$ 
yang masing-masing mempunyai derajat bebas satu. Persamaan (18) merupakan kontribusi prediktor $X_{j}$ bilamana ia ditambahkan ke dalam model yang sebelumnya mengandung $X_{1}, X_{2}, \ldots, X_{j-1}$. (Myers \& Milton, 1991).

Dalam model mediasi sederhana, $X_{j}=M$ dan $X_{j-1}=X$ sehingga model regresi yang terbangun adalah model pada persamaan (3). Penambahan satu peubah $M$ ke dalam model semula (model (1)) akan menyebabkan sebagian dari variasi galat $\varepsilon_{1}$ dapat direduksi oleh adanya peubah baru tersebut. Bagian ini merupakan tambahan bagi variasi model yang dapat disisipkan secara sekuensial dalam tabel ANOVA. Variasi tambahan akibat masuknya $M$ setelah $X$ berada dalam model dapat diukur melalui jumlah kuadrat $(M \mid X)$ dengan memanfaatkan hasil regresi $X$ terhadap $M$. Misalkan jumlah kuadrat regresi model (3) setelah adanya intersep dalam model adalah $J K R\left(c^{\prime}, b \mid i\right)$, dan jumlah kuadrat regresi model (1) setelah adanya intersep dalam model adalah $J K R(c \mid i)$. Berdasarkan skenario ini, prediktor yang masuk terdahulu ke dalam model adalah variabel $X$, kemudian baru ditambahkan variabel $M$, maka kontribusi variabel $M$ adalah:

(19) $J K R(b \mid i, c)=J K R\left(c^{\prime}, b \mid i\right)-J K R(c \mid i)$.

Jumlah kuadrat regresi $M$ dan $X$ terhadap $Y$ setelah adanya intersep dalam model, adalah

(20) $J K R\left(c^{\prime}, b \mid i\right)=(n-1) s_{Y}^{2} R^{2}$

dengan $R^{2}$ dihitung menggunakan persamaan (12). Jumlah kuadrat regresi $X$ terhadap $Y$, model (1), setelah adanya intersep dalam model, adalah

$$
J K R(c \mid i)=(n-1) s_{Y X}\left(s_{X}^{2}\right)^{-1} s_{Y X}
$$

sehingga dengan persamaan (19) dapat diperoleh jumlah kuadrat kontribusi $M \mid X$ terhadap $Y$ yaitu hasil dari (20) dikurangi hasil dari (21).

Selanjutnya, dengan hasil-hasil di atas variabel $K$ dinyatakan dalam prosentase sebagai

$$
K=\frac{J K R(b \mid i, c)}{J K R\left(c^{\prime}, b \mid i\right)} x 100
$$

Oleh karena besarnya kontribusi $K$ tergantung besarnya $b$, dan besaran $b$ adalah salah satu faktor dari besarnya pengaruh mediasi, maka semakin besar $K$ akan semakin besar pula pengaruh mediasinya, yang berarti akan semakin besar juga statistik signifikansi pengaruh mediasi tersebut. Konsistensi hubungan $K$ dengan signifikansi pengaruh mediasinya, dalam penelitian, diuji secara empiris melalui penelusuran pola hubungan linear antara $K$ dan signifikansi pengaruh mediasinya. 


\section{METODOLOGI}

Variabel-variabel dalam penelitian ini adalah tingkat kontribusi variabel mediator $(\mathrm{K})$ dihitung melalui persamaan (22), dan efektivitas mediator (Z) dihitung sebagai statistik Sobel Test (5). Jadi rancangan model dalam penelitian ini adalah hubungan antara $K$ dengan $Z$. Penelitian ini memerlukan sejumlah variabel-variabel pendukung untuk menghasilkan dua variabel utama tersebut. Perhitungan variabel-variabel pendukung menggunakan konsep-konsep sebagaimana telah dikemukakan melalui persamaan-persamaan (4) sampai dengan persamaan (22).

Analisis hubungan sesuai rancangan model tersebut diestimasi menggunakan data simulasi. Analisis terutama disajikan dalam bentuk grafik korelasi $\mathrm{K}$ dengan $\mathrm{Z}$, dan estimasi parameter pengaruh $\mathrm{K}$ terhadap $\mathrm{Z}$. Oleh karena Z kemungkinan mempunyai nilai negatif dan positif, maka dalam penelitian ini digunakan nilai mutlak $Z$. Proses estimasi dan atau simulasi data menggunakan bantuan program aplikasi Microsoft Excel.

Prosedur iterasi pengumpulan/pembangkitan data $\mathrm{K}$ dan $\mathrm{Z}$ dilakukan sebagai berikut: (i) bangkitkan data $X$ dan $Y$ distribusi normal dengan ukuran dan taraf korelasi $X Y$ tertentu, (ii) bangkitkan data $\mathrm{M}$ distribusi normal dengan ukuran yang sama pada (i) dan korelasi XM random, (iii) tentukan nilai $\mathrm{K}$ dan $\mathrm{Z}$ dengan menghitung berbagai statistik menggunakan hasil (i) dan (ii), dan (iv) bangkitkan data $\mathrm{K}$ dan $\mathrm{Z}$ dengan melakukan langkah (ii) dan (iii) sampai iterasi ke- $N$.

Proses iterasi, di dalam Excel, menggunakan fasilitas macro, sedangkan proses pembangkitan data menggunakan fungsi RAND(), NORMINV(), dan CORAND(). Khusus CORAND(), fungsi ini tidak tersedia dalam Excel standar, harus ditambahkan dari perangkat simulasi Simtools yang dikembangkan oleh Myerson (2000) dari Northwestern University.

Analisis data dilakukan dalam tiga taraf korelasi $X Y$, yaitu pada taraf korelasi rendah, sedang, dan tinggi. Untuk mendapat gambaran visual adanya hubungan spesifik antara $\mathrm{K}$ terhadap $Z$, analisis simulasi menggunakan diagram pencar. Lebih lanjut untuk memperoleh gambaran pengaruh secara kuantitatif, estimasi dan analisis model menggunakan pendekatan analisis regresi.

\section{HASIL DAN PEMBAHASAN}

\section{Model Regresi Linear Hubungan Z dengan K}

Data hipotetik distribusi normal untuk $\mathrm{X}$ dan $\mathrm{Y}$ dibangkitkan pada tiga taraf korelasi. Taraf korelasi $X Y$ dipilih tiga macam yaitu taraf korelasi rendah $( \pm 0,25)$, sedang $( \pm 0,50)$, dan tinggi $( \pm 0,75)$. Data untuk $M$ dibangkitkan mengikuti data $X$ dengan korelasi random, dan selanjutnya dengan pendekatan matrik kovariansi dihitung berbagai statistik regresi yang diperlukan untuk dapat menghitung nilai dari variabel $\mathrm{K}$ dan $\mathrm{Z}$. Dalam hal ini, K adalah persen kontribusi jumlah kuadrat $\mathrm{M} \mid \mathrm{X}$ terhadap jumlah kuadrat $Y \mid(X, M)$. Sedangkan $Z$ adalah nilai mutlak statistik uji Sobel.

Setelah dilakukan iterasi pembangkitan data M sebanyak $N=1000$ kali pada setiap jenis taraf korelasi $X Y$, dan setiap iterasi dihitung nilai-nilai $\mathrm{K}$ dan $\mathrm{Z}$, maka diperoleh data hipotetik $\mathrm{K}$ dan $\mathrm{Z}$ dengan plot pencaran dan garis regresi yang masing-masing disajikan pada Gambar 2, 3, dan 4. 


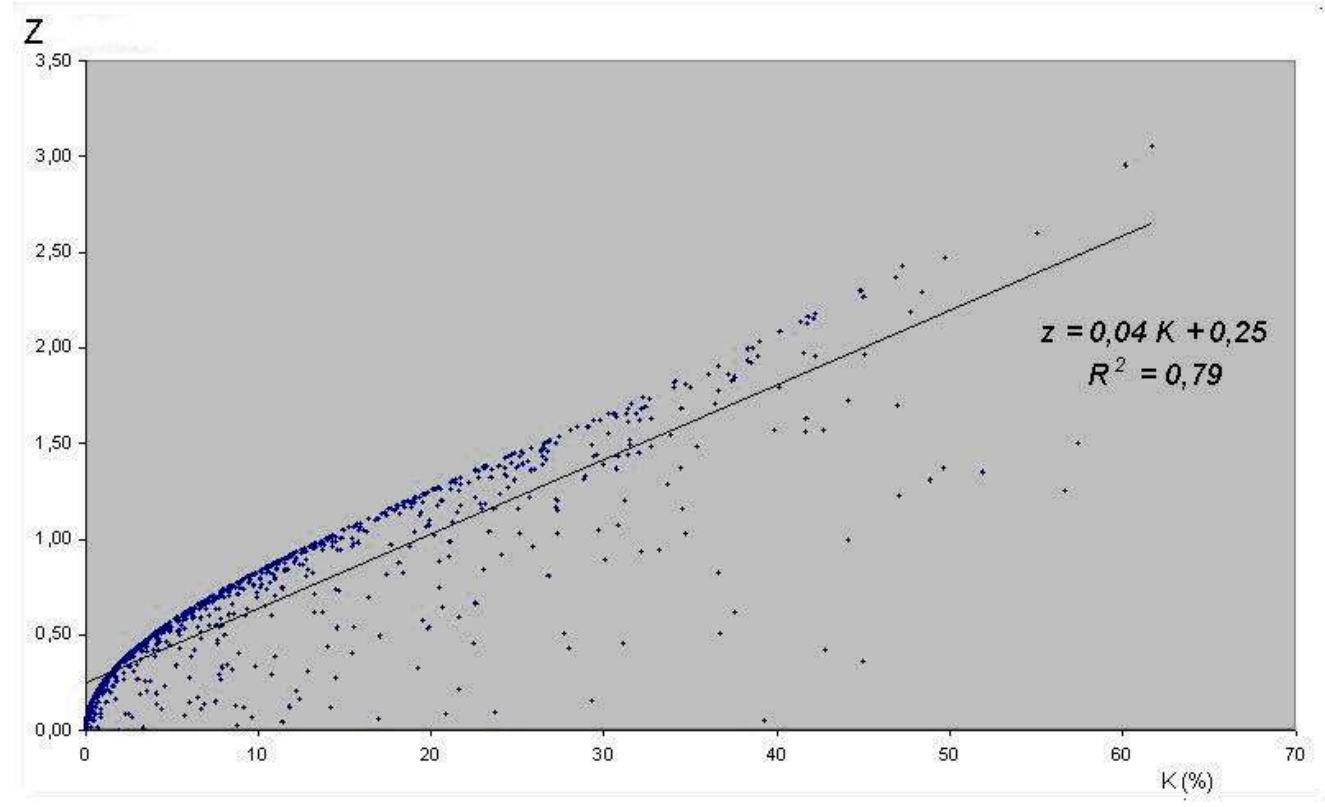

Gambar 2. Plot pencaran kontribusi mediator (K) dan nilai mutlak statistik sobel (Z) pada taraf $r_{X Y}=0,25$, iterasi $N=1000$. Taksiran garis regresi $\hat{Z}=0,25+0,04 K$.

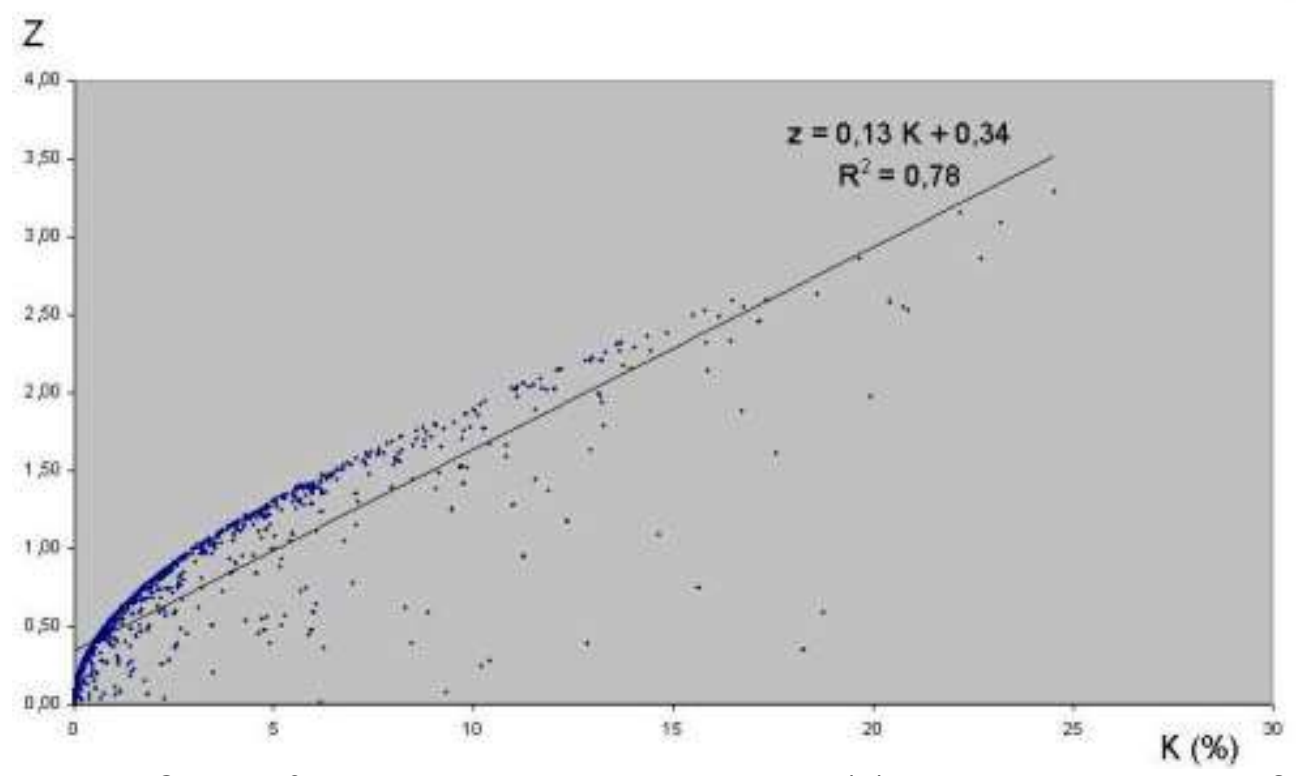

Gambar 3. Plot pencaran kontribusi mediator (K) dan nilai mutlak statistik Sobel ( $\mathrm{Z}$ ) pada taraf $r_{X Y}=0,50$, iterasi $N=1000$. Taksiran garis regresi $\hat{Z}=0,34+0,13 K$. 


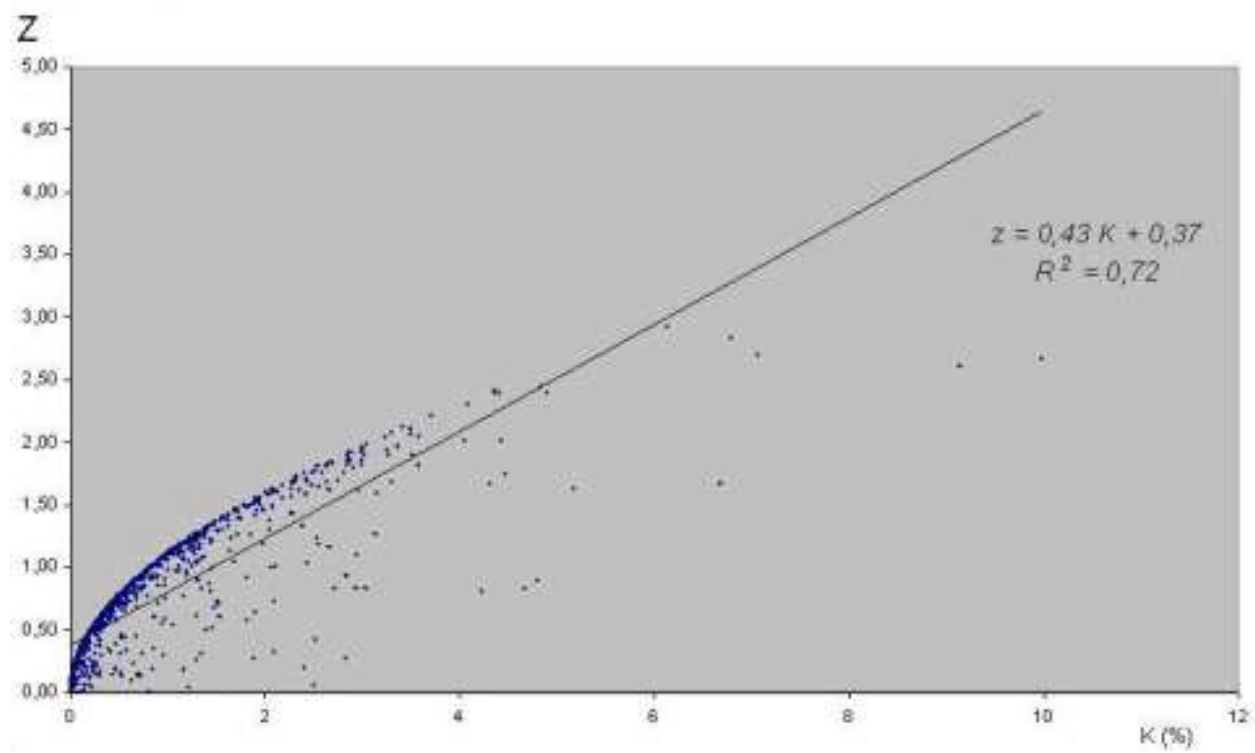

Gambar 4. Plot pencaran kontribusi mediator (K) dan nilai mutlak statistik Sobel (Z) pada taraf $r_{X Y}=0,75$, iterasi $N=1000$. Taksiran garis regresi $\hat{Z}=0,37+0,43 K$.

\section{Kontribusi Mediator terhadap Efektivitasnya}

Hubungan kontribusi variabel mediator dengan efektivitasnya sebagaimana pada Gambar 2, 3 , dan 4, menunjukkan kesan pola hubungan bersifat linear dan eksponensial; kesan eksponensial terutama pada nilai kontribusi yang rendah. Perbedaan pada setiap gambar menunjukkan bahwa derajat hubungan $\mathrm{K}$ dengan $\mathrm{Z}$ tergantung pada korelasi antara $\mathrm{X}$ dengan $\mathrm{Y}$. Hubungan interaksi antara $K$ dengan $r_{X Y}$ terhadap $Z$ terlihat lebih jelas dengan mengepas garis lurus nilai-nilai $Z$ untuk berbagai nilai K. Koefisien garis lebih "landai" sejalan dengan semakin rendahnya $r_{X Y}$. Koefisien garis pada taraf $\mathrm{rXY}$ rendah, sedang, dan tinggi, masing-masing adalah $0,04,0,13$, dan 0,43 . Artinya, diperlukan kontribusi yang semakin tinggi dari $\mathrm{M}$ bagi model mediasi sederhana yang mempunyai korelasi antara $\mathrm{X}$ dan $\mathrm{Y}$ yang semakin rendah, untuk tingkat efektivitas mediasi yang sama.

Tingkat kontribusi $\mathrm{M}$ dalam model mediasi sederhana yang diperlukan agar pengaruh mediasinya efektif, pada taraf-taraf korelasi $X Y$ tertentu disajikan pada Tabel 1. Nilai $Z=1,64$ menunjukkan titik kritis efektivitas pengaruh mediasi pada tingkat signifikan $a=10 \%$. Nilai $Z=1,96$ menunjukkan titik kritis efektivitas pengaruh mediasi pada tingkat signifikan $\alpha=5 \%$. Nilai-nilai $\mathrm{K}$ untuk titik kritis efektivitas $Z=1,96$ pada tiga jenis taraf korelasi $X Y$ masing-masing adalah $44 \%$, $12,5 \%$, dan 3,7\%. Artinya, kira-kira, diperlukan tingkat kontribusi lebih dari $40 \%$ bagi variabel mediator (M) agar pengaruh mediasinya efektif, jika korelasi antara $X$ dengan $Y$ rendah. Jika korelasi $X Y$ tinggi, diperlukan tingkat kontribusi M kira-kira 4\%. Pada taraf sedang, kira-kira diperlukan kontribusi $12 \%$. Hasil penelitian ini menunjukkan bahwa agar M efektif dalam model mediasi sederhana, maka kontribusi M harus semakin besar jika korelasi XY semakin rendah. 
Tabel 1. Nilai K untuk Nilai Z Efektif, pada Taraf-taraf Korelasi XY

\begin{tabular}{ccccc}
\hline Taraf & & & \multicolumn{2}{c}{ Nilai K (\%) untuk } \\
Korelasi XY & $r_{X Y}$ & Model & $\hat{Z}=1,64$ & $\hat{Z}=1,96$ \\
\hline Rendah & 0,25 & $\hat{Z}=0,25+0,04 K$ & 35,8 & 44,0 \\
Sedang & 0,50 & $\hat{Z}=0,34+0,13 K$ & 10,1 & 12,5 \\
Tinggi & 0,75 & $\hat{Z}=0,37+0,43 K$ & 3,0 & 3,7 \\
\hline
\end{tabular}

\section{Kajian Teoritis vs Empirik}

Secara teoritis, pengaruh mediasi variabel mediator $(M)$ tergantung korelasinya dengan $X$ dan $Y$, serta korelasi $X$ dengan $Y$. Besaran ini diwakili oleh nilai a, b, dan c dalam Gambar 1. Jika semua korelasi ini signifikan, maka signifikansi pengaruh mediasi tergantung kecilnya variansi masing-masing a dan $\mathrm{b}$. Pengaruh mediasi yang signifikan menunjukkan bahwa keberadaan $\mathrm{M}$ yang efektif dalam model mediasi sederhana, mereduksi dengan cukup besar (yakni sebesar ab) peranan $X$ dalam model (dari $\mathrm{c}$ menjadi c'). Nilai ab akan relatif lebih besar dibandingkan dengan nilai $\mathrm{c}$ model mediasi sederhana dengan $r_{x y}$ lebih rendah, daripada dengan nilai $\mathrm{c}$ model mediasi sederhana dengan $r_{X Y}$ lebih tinggi. Artinya, pada model mediasi sederhana dengan korelasi $X Y$ rendah, keberadaan mediator M lebih efektif (berperan) daripada mediator tersebut berada pada model mediasi sederhana dengan korelasi XY tinggi.

Jadi, keberadaan $M$ dalam model mediasi sederhana akan besar peranannya jika $X$ dan $Y$ berkorelasi rendah. Sebaliknya untuk $\mathrm{X}$ dan $\mathrm{Y}$ yang berkorelasi tinggi maka keberadaan $\mathrm{M}$ menjadi tidak terlalu berperan.

Hasil empiris, dalam penelitian ini, menunjukkan bahwa agar M efektif dalam model mediasi sederhana, maka kontribusi M harus semakin besar jika korelasi XY semakin rendah. Keadaan ini sesuai secara teoritis karena kontribusi M yang lebih besar, pengaruh mediasinya akan lebih besar, dan menunjukkan bahwa M semakin berperan dalam model mediasi sederhana.

Semakin besar kontribusi M akan menyebabkan nilai c' (model (3)) mengecil, dan akan semakin kecil lagi jika korelasi XY rendah. Pada model dengan korelasi XY yang sangat rendah maka semakin besar kontribusi M akan menyebabkan nilai c' mendekati nol, artinya mediasi yang terjadi akan lebih mengarah ke mediasi sempurna. Sedangkan jika korelasi $X Y$ tinggi, mediasi yang terjadi bersifat mediasi parsial karena kemungkinan nilai c' tidak akan mencapai nol.

\section{KESIMPULAN}

Hasil penelitian ini menunjukkan bahwa efektivitas suatu variabel mediator dalam model mediasi sederhana dipengaruhi oleh kontribusinya. Efektivitas variabel mediator yang ditunjukkan oleh signifikansi pengaruh mediasi bergantung pada besar kecilnya kontribusi variabel mediator tersebut dalam model. Pengaruh kontribusi mediator terhadap efektivitasnya tersebut bergantung juga pada tingkat korelasi model awal (model sederhana hubungan antara X dan Y). Pada tingkat korelasi XY rendah, pengaruh mediasi variabel mediator efektif jika kontribusinya cukup besar. Sebaliknya, pada tingkat korelasi XY tinggi, pengaruh mediasi variabel mediator efektif walau kontribusinya kecil. Pada berbagai taraf korelasi XY tersebut, pengaruh kontribusi terhadap 
efektivitas secara umum tetap sama bahwa semakin besar kontribusi maka semakin besar efektivitasnya sebagai variabel mediator.

\section{REFERENSI}

Baron, R. M., \& Kenny, D. A. (1986). The moderator-mediator variable distinction in social psychological research: Conceptual, strategic, and statistical considerations. Journal of Personality and Social Psychology, 51, 1173-1182.

James, L. R., \& Brett, J. M. (1984). Mediators, moderators, and tests for mediation. Journal of Applied Psychology, 69, 307-321.

MacKinnon, D. P., \& Dwyer, J. H. (1993). Estimating mediated effects in prevention studies. Evaluation Review, 17, 144-158.

MacKinnon, D. P., Warsi, G., \& Dwyer, J. H. (1995). A simulation study of mediated effect measures. Multivariate Behavioral Research, 30(1), 41-62.

Morrison, D. F. (1990). Multivariate statistical methods (3rd ed). Singapore: McGraw-Hill.

Myers, R. H., \& Milton, J.S. (1991). A first course in the theory of linear statistical models. Boston: PWS-Kent.

Myerson, R. B. (2000). Simtools (3.31a). Northwestern University : Kellog Scholl of Management. Diambil 4 Agustus 2000, dari http://www.kellogg.nwu.edu/faculty/myerson/ttp/addins.htm.

Preacher, K. J., \& Hayes, A. F. (2004). SPSS and SAS procedures for estimating indirect effects in simple mediation models. Behavior Research Methods, Instruments, \& Computers, 36(4), 717-731.

Sobel, M. E. (1982). Asymptotic intervals for indirect effects in structural equations models. Dalam S. Leinhart (Editor), Sociological Methodology 1982, pp.290-312. San Francisco: Jossey-Bass.

Preacher, K. J., \& Leonardelli, G. J. (2006). Calculation for the sobel test: An interactive calculation tool for mediation tests. Diambil 22 Januari 2008, dari

http://people.ku.edu/ preacher/sobel/sobel.htm. 